\title{
A NONINVASIVE INCLUSION OF SYNCHROPHASORS IN THE POWER SYSTEM STATE ESTIMATION
}

\author{
Vedran Kirincic, Srdjan Skok, Dubravko Frankovic
}

Original scientific paper

The paper investigates the application of synchronized phasor measurements, which are available from Phasor Measurement Units (PMUs), in the power system state estimation. In order to avoid changes in the type of the input measurements of the classical state estimator, which runs in the control centre, the proposed model utilizes voltage and current phasors to calculate pseudo-measurements such as pseudo-voltages, power flows and power injections. These pseudo-measurements are used together with the voltage phasor magnitudes and the conventional measurements in the iterative procedure. The IEEE 14, 30, 57 and 118 buses test systems as well as the mathematical model of the Croatian transmission power system were used as the test systems. The results of the simulation were compared with the classical state estimator, which uses only conventional measurements. The effect of the voltage phasor angles on the state estimator performance was investigated.

Keywords: hybrid state estimator; Phasor Measurement Unit (PMU); power system state estimation; synchronized measurement technology

\section{Neinvazivna primjena sinkroniziranih mjerenja fazora u estimaciji stanja elektroenergetskog sustava}

Izvorni znanstveni članak

Rad istražuje primjenu sinkroniziranih mjerenja fazora, dostupnih iz jedinica za sinkronizirano mjerenja fazora (PMU), $u$ estimaciji stanja elektroenergetskog sustava. Kako bi se izbjegla promjena vrste mjerenja koja ulaze u klasičan estimator stanja korišten u centru vođenja, predloženi model koristi fazore napona i struje za izračun pseudo mjerenja poput pseudo-napona, tokova snage i injekcija snage. Izračunata se pseudo-mjerenja zatim zajedno s amplitudama fazora napona te konvencionalnim mjerenjima primjenjuju u iterativnoj proceduri. Kao test sustavi korišteni su IEEE test sustavi s 14, 30, 57 i 118 čvorišta, kao i matematički model hrvatskog prijenosnog elektroenergetskog sustava. Rezultati dobiveni simulacijom su uspoređeni s rezultatima klasičnog estimatora stanja, koji koristi samo konvencionalna mjerenja. U radu je istražen utjecaj kuta fazora napona na performanse estimatora stanja.

Ključne riječi: estimacija stanja elektroenergetskog sustava; hibridni estimator stanja; jedinica za sinkronizirano mjerenje fazora; tehnologija sinkroniziranih mjerenja fazora

\section{Introduction}

Due to the strong pressure on the aging infrastructure to deliver the electric energy to its consumers without interruptions, the power system faces many challenges. In addition to the lowered security margins, the intensive integration of intermittent renewable energy sources introduces uncertainties in the power system operation, which can result in large cascading blackouts. The synchronized measurement technology (SMT) is recognized in the development of Smart Transmission Grid solutions that would help utilities to cope with the oncoming requests on the power system operation [1]. Therefore, utilities worldwide started to populate their networks with Phasor Measurement Units (PMUs) that use GPS signals to synchronize a real-time process of measuring geographically dislocated voltage and current phasors. The availability of the synchrophasors presents the basis for the development of Wide Area Monitoring, Protection and Control (WAMPAC) systems [2].

Being a key application in the Energy Management System (EMS), the state estimator provides an optimal solution for the power system state, which consists of voltage phasors at all the buses in the power system. Assuming that the power system is completely observable by a sufficient number of the PMUs that are optimally placed in the system to ensure the complete system observability, the above described still being a futuristic scenario, the state estimator formulation becomes linear. A more realistic solution are hybrid models that combine the synchrophasors with the conventional measurements provided by the Supervisory Control And Data Acquisition (SCADA) system.

The optimal inclusion of the synchrophasors into the state estimator set of measurements is one of the major challenges investigated by many researchers. The state estimator proposed in literature [3] transforms the phasors of current from polar to rectangular coordinates to avoid convergence issues of the iterative procedure. In order to avoid the transformation of measurements and the associated propagation of measurement uncertainties, the hybrid model in [4] introduces a set of constraints to relate the phasors of current with the bus voltages. Since there are reported convergence issues when the current phasors are used directly as a part of the measurement vector [5], they are preferably used together with the voltage phasors in order to obtain pseudo-measurements. Therefore, the state estimator proposed in [6] calculates the pseudo-voltages at the buses adjacent to PMU buses by using the voltage and current phasors and the known parameters of the branches. The models given in $[7,8]$ calculate the power flows on the branches emerging from the PMU buses and the power injections on the PMU buses, respectively.

The power utilities implement modern technologies gradually and often years or even decades pass until the migration from the existing towards new solutions is completed. In the last decade, the Croatian Transmission System Operator (TSO) deployed PMUs and built a Wide Area Monitoring System (WAMS) enhanced with the originally developed phasor data concentrator (PDC). The classical state estimator, which runs in the Croatian control centre, is based on the Weighted Least Squares 
(WLS) method and uses the conventional SCADA measurements such as voltage magnitudes, power injections and power flows. When considering possible solutions for the inclusion of the synchrophasors into the state estimation process, it became clear that the drawback of the hybrid state estimators that process the conventional measurements and the synchrophasors at the same time, is that they require substantial modifications of the EMS software. Consequently, an evolutionary approach is investigated in order to take advantage of the synchrophasors, without changing the type of the input measurements of the existing classical model. The effect on hybrid state estimator performance by various types of the calculated pseudo-measurements and the measured PMU voltages is investigated.

Section 2 presents a classical approach to the power system state estimation and Section 3 introduces the mathematical model of the hybrid state estimator. Section 4 gives the description of the power systems and the assessment criteria that were used to test the state estimators. In Section 5 the results of the simulation are given, while Section 6 concludes the paper.

\section{Classical solution to power system state estimation}

The classical solution to power system state estimation is based on the WLS method that is briefly explained for the completeness of the paper. The complete overview of the classical state estimation theory can be found in $[9,10]$. The structure of the measurement vector filled with the conventional SCADA measurements is given as:

$\boldsymbol{z}=\left[\boldsymbol{V}, \boldsymbol{P}_{\text {flow }}, \boldsymbol{Q}_{\text {flow }}, \boldsymbol{P}_{\text {inj }}, \boldsymbol{Q}_{\text {inj }}\right]^{\mathrm{T}}=\boldsymbol{z}_{\text {conv }}$,

where $\boldsymbol{V}$ is the vector of voltage magnitudes, $\boldsymbol{P}_{\text {flow }}$ and $\boldsymbol{Q}_{\text {flow }}$ are the vectors of active and reactive power flows, while $\boldsymbol{P}_{\text {inj }}$ and $\boldsymbol{Q}_{\text {inj }}$ are the vectors of active and reactive power injections.

The state vector $\boldsymbol{x}=[\boldsymbol{\theta}, \boldsymbol{V}]^{\mathrm{T}}$ comprises voltage magnitudes and angles at all the buses in the system. There is a nonlinear relationship between the elements of the state vector and the power flows and injections that are a part of the measurement vector $\mathbf{z}$, which is expressed through the vector of nonlinear equations $\boldsymbol{h}(\boldsymbol{x})$ :

$\boldsymbol{z}=\boldsymbol{h}(\boldsymbol{x})+\boldsymbol{e}$,

where $\boldsymbol{e}$ is the error vector of uncorrelated measurement errors with the Gaussian distribution.

Considering different accuracy for each type of measurement, measurement weights are introduced through the measurement error covariance matrix $\boldsymbol{R}=\operatorname{diag}\left\{\sigma_{1}^{2}, \ldots, \sigma_{m}^{2}\right\}$, where $\sigma$ is the standard deviation and $m$ is the number of measurements. The maximum uncertainties $\Delta u$ are usually provided by the equipment manufacturer. If a uniform probability distribution over the entire range of uncertainty is assumed, the expression to obtain the standard uncertainties in the measurements follows [9, 11]:
$\sigma=\frac{\Delta u}{\sqrt{3}}$

The optimal solution in terms of the power system state estimation is obtained by minimizing the objective function $J(\boldsymbol{x})$ :

$\min J(\boldsymbol{x})=\frac{1}{2}[\boldsymbol{z}-\boldsymbol{h}(\boldsymbol{x})]^{\mathrm{T}} \boldsymbol{R}^{-1}[\boldsymbol{z}-\boldsymbol{h}(\boldsymbol{x})]$.

To estimate the power system state closest to the true state, the iterative procedure is applied. The Jacobian matrix $\boldsymbol{H}=\frac{\partial \boldsymbol{h}(\boldsymbol{x})}{\partial \boldsymbol{x}}$ and the Gain matrix $\boldsymbol{G}\left(\boldsymbol{x}^{k}\right)=\boldsymbol{H}^{\mathrm{T}}\left(\boldsymbol{x}^{k}\right) \cdot \boldsymbol{R}^{-1} \boldsymbol{H}\left(\boldsymbol{x}^{k}\right)$ are introduced, where $\boldsymbol{x}^{k}$ is the state vector in the $k^{\text {th }}$ iteration. The change of the state vector $\Delta \boldsymbol{x}^{k}$ is updated in each iteration:

$\boldsymbol{G}\left(\boldsymbol{x}^{k}\right) \Delta \boldsymbol{x}^{k}=\boldsymbol{H}^{\mathrm{T}}\left(\boldsymbol{x}^{k}\right) \cdot \boldsymbol{R}^{-1}\left[\boldsymbol{z}-\left(\boldsymbol{x}^{k}\right)\right]$,

$\Delta \boldsymbol{x}^{k}=\boldsymbol{x}^{k+1}-\boldsymbol{x}^{k}$

until it becomes smaller than the set tolerance.

To alleviate the issue of ill-conditioning of the Gain matrix due to high weights of extremely accurate measurements [9] such as zero-injections, a set of constraints is introduced:

$L(\boldsymbol{x}, \lambda)=\frac{1}{2}[\boldsymbol{z}-\boldsymbol{h}(\boldsymbol{x})]^{\mathrm{T}} \boldsymbol{R}^{-1}[\boldsymbol{z}-\boldsymbol{h}(\boldsymbol{x})]-\lambda^{\mathrm{T}} \boldsymbol{c}(\boldsymbol{x})$,

s.t. $\boldsymbol{c}(\boldsymbol{x})=0$,

where $\lambda$ is a vector of the Lagrange multipliers. To minimize $L(x, \lambda)$, the first-order optimality conditions $\partial L(\boldsymbol{x}, \lambda) / \partial \boldsymbol{x}=0$ and $\partial L(\boldsymbol{x}, \lambda) / \partial \boldsymbol{\lambda}=0$ should be satisfied. With $\boldsymbol{C}=\partial \boldsymbol{c}(\boldsymbol{x}) / \partial \boldsymbol{x}$ and $\Delta \boldsymbol{x}=\boldsymbol{x}^{k+1}-\boldsymbol{x}^{k}$, the solution for $\Delta x$ and $\lambda$ is obtained using the Gauss-Newton method:

$$
\left[\begin{array}{cc}
\boldsymbol{H}^{\mathrm{T}} \boldsymbol{R}^{-1} \boldsymbol{H} & \boldsymbol{C}^{\mathrm{T}} \\
\boldsymbol{C} & 0
\end{array}\right]\left[\begin{array}{c}
\Delta \boldsymbol{x} \\
-\lambda
\end{array}\right]=\left[\begin{array}{c}
\boldsymbol{H}^{\mathrm{T}} \boldsymbol{R}^{-1}\left(\boldsymbol{z}-\boldsymbol{h}\left(\boldsymbol{x}^{k}\right)\right) \\
-\boldsymbol{c}\left(\boldsymbol{x}^{k}\right)
\end{array}\right] .
$$

\section{Structure of hybrid state estimator}

Let us consider a pi-model of the network branch given in Fig. 1.

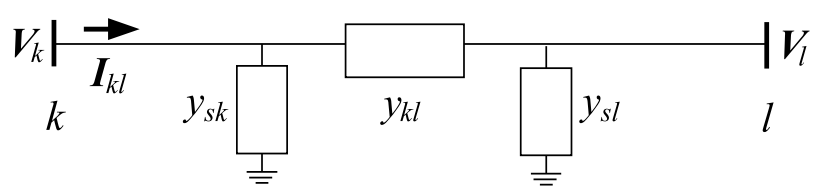

Figure 1 A pi-model of the network branch

Here, $y_{k l}=g_{k l}+j b_{k l}$ is the series admittance of the branch and $y_{s k}=g_{s k}+j b_{s k}$ and $y_{s l}=g_{s k}+j b_{s k}$ are the shunt admittances. Assuming there is a PMU at the bus $k$, the voltage $\boldsymbol{V}_{k}=V_{k} \angle \theta_{k}$, and the current $\boldsymbol{I}_{k l}=I_{k l} \angle \theta_{k l}$, synchrophasors are measured and sent to the control center, where $V_{k}$ and $\theta_{k}$ are the magnitude and angle of the voltage at the PMU bus, while $I_{k l}$ and $\theta_{k l}$ are the 
magnitude and angle of the current on the branch emerging from the PMU bus. Using the measured voltage and current synchrophasors, one can calculate the voltages $\boldsymbol{V}_{\mathrm{ps}}=V_{\mathrm{ps} m} \angle \theta_{\mathrm{ps} a}$, at the buses adjacent to the PMU buses, the pairs of active and reactive pseudoinjections $\boldsymbol{P} \boldsymbol{Q}_{\text {injps }}$ at the PMU buses and the pairs of active and reactive pseudo-flows $\boldsymbol{P} \boldsymbol{Q}_{\mathrm{fl} p s}$ on the branches emerging from the PMU buses. Since these values are not directly measured but calculated, they are noted as pseudo-measurements.

The pseudo-voltages $\boldsymbol{V}_{\mathrm{ps}}$ at the buses adjacent to the PMU buses are obtained using the expression given in [6]

$$
\boldsymbol{V}_{l}=\frac{\boldsymbol{V}_{k}\left(g_{k l}+j b_{k l}+g_{s k}+j b_{s k}\right)-\boldsymbol{I}_{k l}}{g_{k l}+j b_{k l}}=V_{l} \angle \theta_{l},
$$

where $V_{l}$ and $\theta_{l}$ are the magnitude and angle of the voltage at the bus adjacent to the PMU bus.

The pseudo-power flow $\boldsymbol{P} \boldsymbol{Q}_{\text {flps }}$ on the branch connecting the buses $k$ and $l$ is obtained as suggested in [7]. Taking the real and the imaginary part, the active $P_{k l}$ and reactive $Q_{k l}$ pseudo-power flows are obtained:

$P_{k l}=V_{k} \cdot I_{k l} \cdot \cos \left(\theta_{k}-\theta_{k l}\right)$,

$Q_{k l}=V_{k} \cdot I_{k l} \cdot \sin \left(\theta_{k}-\theta_{k l}\right)$.

To calculate the pseudo-injections $\boldsymbol{P} \boldsymbol{Q}_{\text {injps }}$ at the
PMU buses, the voltage phasor at the PMU buses and the current phasors from all the branches emerging from the PMU buses should be available, which is usually the case since the modern PMUs have enough measurement channels [13]. As given in [8], for each PMU bus the currents phasors measured on $n$ coincident branches are transformed from polar to rectangular coordinates and summed:

$$
\boldsymbol{I}_{k}=I_{k} \angle \theta_{I k}=\sum_{i=1}^{n} \boldsymbol{I}_{k n}
$$

The pseudo-power injections at the bus $k$ are calculated as:

$$
\begin{aligned}
& P_{k}=V_{k} \cdot I_{k} \cdot \cos \left(\theta_{V k}-\theta_{I k}\right), \\
& Q_{k}=V_{k} \cdot I_{k} \cdot \sin \left(\theta_{V k}-\theta_{I k}\right) .
\end{aligned}
$$

In order to assign proper weight factors to the obtained pseudo-measurements, the classical measurement uncertainty propagation theory is applied [12]

To investigate the impact of the measured voltage magnitude and angle as well as the computed pseudo-

\begin{tabular}{|c|c|c|c|c|c|c|c|}
\hline \multirow{6}{*}{$\boldsymbol{z}_{h y}=$} & Set 1 & Set 2 & Set 3 & Set 4 & Set 5 & Set 6 & Set 7 \\
\hline & $\boldsymbol{z}_{\text {conv }}$ & $\boldsymbol{z}_{\text {conv }}$ & $\boldsymbol{z}_{\text {conv }}$ & $\boldsymbol{z}_{\text {conv }}$ & $\boldsymbol{z}_{\text {conv }}$ & $\boldsymbol{z}_{\text {conv }}$ & $\boldsymbol{z}_{\text {conv }}$ \\
\hline & 0 & $\boldsymbol{V}_{\mathrm{PMU} m}$ & 0 & 0 & 0 & $\boldsymbol{V}_{\mathrm{PMU} m}$ & $\boldsymbol{V}_{\mathrm{PMU}}$ \\
\hline & 0 & 0 & $\boldsymbol{V}_{\mathrm{ps} m}$ & 0 & 0 & $\boldsymbol{V}_{\mathrm{ps} m}$ & $\boldsymbol{V}_{\mathrm{ps}}$ \\
\hline & 0 & 0 & 0 & $\boldsymbol{P} \boldsymbol{Q}_{\text {injps }}$ & 0 & $\boldsymbol{P} \boldsymbol{Q}_{\text {injps }}$ & $\boldsymbol{P} \boldsymbol{Q}_{\text {injps }}$ \\
\hline & 0 & 0 & 0 & 0 & $\boldsymbol{P} \boldsymbol{Q}_{\mathrm{fl} \mathrm{ps}}$ & $\boldsymbol{P} \boldsymbol{Q}_{\mathrm{fl} \mathrm{ps}}$ & $\boldsymbol{P} \boldsymbol{Q}_{\mathrm{flps}}$ \\
\hline
\end{tabular}
measurements on the state estimator performance, the structure of the measurement vector was changed as given: where Set 1 - Set 7 are different sets of measurements.

In order to avoid changing the type of measurements used in the existing classical state estimator, the vectors $\boldsymbol{V}_{\mathrm{PMU} m}$ (in the Set 2 and Set 6 ) and $\boldsymbol{V}_{\mathrm{ps} m}$ (in the Set 3 and Set 6 ) consist of the voltage magnitudes measured by the PMUs and the magnitudes of the computed pseudovoltages, respectively. To investigate the effect of the voltage angles on the state estimator performance the Set 7 takes $\boldsymbol{V}_{\mathrm{PMU}}$ and $\boldsymbol{V}_{\mathrm{ps}}$ that comprise both the voltage magnitudes and the angles of the voltage phasors measured by the PMUs and the computed pseudovoltages, respectively. It has to be emphasized that the Set 7 requires a change of the structure of the state estimator since the voltage angles are usually not taken as a part of the classical state estimator measurement vector, and therefore, modifications in the Jacobian matrix are necessary.

For measurements other than the voltage magnitudes the relationship between the measurements and the state vector elements is nonlinear; therefore the iterative WLS method presented in the previous section is applied to obtain the state estimate.

\section{Case studies}

The power flow calculation was run in order to obtain the set of true measurements. The additive random Gaussian noise with a zero mean was used to obtain the noisy measurements. In Tab. 1 the maximum measurement uncertainties are given.

Table 1 Maximum measurement uncertainties

\begin{tabular}{|c|c|c|c|c|}
\hline \multicolumn{3}{|c|}{ PMU measuremts } & \multicolumn{2}{c|}{ SCADA measurements } \\
\hline $\begin{array}{c}\text { Voltage } \\
\text { magnitude } \\
(\%)\end{array}$ & $\begin{array}{c}\text { Current } \\
\text { magnitude } \\
(\%)\end{array}$ & $\begin{array}{c}\text { Voltage and } \\
\text { current } \\
\text { phase angle } \\
\left({ }^{\circ}\right)\end{array}$ & $\begin{array}{c}\text { Voltage } \\
\text { magnitude } \\
(\%)\end{array}$ & $\begin{array}{c}\text { Power flow } \\
\text { and power } \\
\text { injection } \\
(\%)\end{array}$ \\
\hline 0,02 & 0,03 & 0,01 & 0,2 & 2 \\
\hline
\end{tabular}

The variance of $L$ estimated state variables was used as the measure of the state estimator accuracy:

$$
\sigma_{\Sigma}^{2}=\frac{1}{M} \sum_{j=1}^{L} \sum_{i=1}^{M}\left(\boldsymbol{x}(j)-\hat{\boldsymbol{x}}(j)_{(i)}\right)^{2}
$$


where $\boldsymbol{x}$ is the vector of true states and $\hat{\boldsymbol{x}}$ is the vector of estimated states.

The following filtering index was used as the measure of the filtering of the errors of $m$ measurements:

$$
\xi(\hat{x})=\frac{1}{M} \sum_{i=1}^{M} \frac{\sum_{j=1}^{m}\left(\hat{z}_{j}-z_{j}^{\text {true }}\right)^{2}}{\sum_{j=1}^{m}\left(z_{j}-z_{j}^{\text {true }}\right)^{2}},
$$

where $\hat{z}, z$ and $z^{\text {true }}$ are the calculated values based on the estimated state vector, the noisy measurements and the true values, respectively.

The convergence and speed of calculation are presented through the number of iterations and the computation time needed to reach the tolerance of $10^{-6}$.

Table 2 Locations of measurements for the IEEE 14 test system

\begin{tabular}{|l|l|}
\hline \multicolumn{1}{|c|}{ Measurement type } & \multicolumn{1}{c|}{ Measurement location } \\
\hline Voltage phasor (\# bus) & 1,6 \\
\hline Current phasor (\#from-\#to) & $1-2,1-5,6-5,6-11,6-12,6-13$ \\
\hline Voltage magnitude (\#bus) & $2,3,8,10,12$ \\
\hline Power flow (\#from-\#to) & $1-2,4-7,4-9,5-6,6-12,6-13,7-9,13-$ \\
& 14 \\
\hline Power injection (\#bus) & $1,2,3,4,6,8,9,10,11,12,13,14$ \\
\hline
\end{tabular}

Table 3 Locations of measurements for the IEEE 30 test system

\begin{tabular}{|l|l|}
\hline \multicolumn{1}{|c|}{ Measurement type } & \multicolumn{1}{|c|}{ Measurement location } \\
\hline Voltage phasor (\# bus) & $1,4,5,7,9,14,15,16,17$ \\
\hline & $1-2,1-3,4-6,5-7,9-11,9-10,4-12,14-$ \\
Current phasor(\#from-\#to) & $15,16-17,15-18,15-23,4-2,4-3,5-2$, \\
& $7-5,7-6,9-6,14-12,15-12,16-12,15-$ \\
& $14,17-16,17-10$ \\
\hline Voltage magnitude (\#bus) & $2,3,6,9,11,14,16,17,25,30$ \\
\hline & $1-3,2-4,2-6,4-6,5-7,6-8,6-9,6-10$, \\
Power flow (\#from-\#to) & $12-13,12-15,14-15,16-17,15-18,10-$ \\
& $20,10-17,15-23,25-26,25-27,28-27$, \\
\hline \multirow{2}{*}{ Power injection (\#bus) } & $1,2,4,6,6,10,11,12,15,18,19,24,25$, \\
\hline
\end{tabular}

Table 4 Locations of measurements for the IEEE 57 test system

\begin{tabular}{|l|l|}
\hline \multicolumn{1}{|c|}{ Measurement type } & \multicolumn{1}{|c|}{ Measurement location } \\
\hline Voltage phasor (\# bus) & $1,3,5,8,10,11,13,14,15,16,18,41$, \\
& 42,57 \\
\hline & $1-2,3-4,8-9,13-14,13-15,1-15,1-16$, \\
& $1-17,3-15,5-6,10-12,11-13,14-15$, \\
& $18-19,11-41,41-42,41-43,15-45,14-$ \\
& $46,10-51,13-49,11-43,57-56,3-2,5-$ \\
Current phasor (\#from-\#to) & $4,8-6,10-9,11-9,13-9,14-13,15-13$, \\
& $15-1,16-1,15-3,18-4,18-4,8-7,13-11$, \\
& $13-12,16-12,15-14,41-11,42-41,41-$ \\
& $56,42-56,57-39$ \\
\hline \multirow{2}{*}{ Voltage magnitude (\#bus) } & $1,3,4,5,7,8,11,15,17,22,27,31$, \\
& $37,44,52,54$ \\
\hline \multirow{5}{*}{ Power flow (\#from-\#to) } & $1-15,1-17,2-3,3-4,4-5,4-18,6-7,7-8$, \\
& $7-29,8-9,9-10,9-11,9-12,9-13,12-16$, \\
& $12-17,13-15,14-15,14-46,18-19,22-$ \\
& $23,22-38,24-25,28-29,24-26,26-27$, \\
& $32-33,35-36,38-48,46-47,52-29,52-$ \\
\hline \multirow{3}{*}{ Power injection (\#bus) } & 53 \\
\hline & $1,2,5,6,10,12,13,15,18,19,25,27$, \\
& $30,32,35,41,43,44,47,49,51,53$, \\
\hline
\end{tabular}

The test systems used were the IEEE test systems with 14, 30, 57 and 118 buses [14] as well as the mathematical model of the Croatian transmission power system. The locations of the conventional measurements for the IEEE test systems were chosen in order to completely observe the whole power system, while the PMUs were placed in order to increase the redundancy of the measurements. The locations of the conventional measurements and the PMUs for the IEEE test systems are given in Tabs. $2 \div 5$. For the model of the Croatian transmission power system, the real locations of conventional and PMU measurements were used.

\section{Results}

In this section the results obtained using the case studies and the hybrid estimator described in previous sections are given. The simulations were carried out using an Intel ${ }^{\circledR}$ Core (TM) 2 Duo E8400 at $3.0 \mathrm{GHz}$ CPU with $4 \mathrm{~GB}$ of RAM. In order to gain unbiased results, the average of $M=100$ Monte Carlo trials was taken, each time with a different set of random noise. The results obtained by using different sets of measurements for the test systems are given in Tabs. $6 \div 10$.

Table 5 Locations of measurements for the IEEE 118 test system

\begin{tabular}{|c|l|}
\hline \multicolumn{1}{|c|}{ Measurement type } & \multicolumn{1}{|c|}{ Measurement location } \\
\hline Voltage phasor(\# bus) & $24,40,59,69,75,80,100,103,113$, \\
& 114 \\
\hline & $40-41,40-42,59-60,59-61,69-70,24-$ \\
& $70,24-72,69-75,69-77,75-77,80-96$, \\
& $80-97,80-98,80-99,100-101,100-103$, \\
& $100-104,103-104,103-105,100-106$, \\
Current phasor (\#from-\#to) & $103-110,114-115,75-118,24-23,40-$ \\
& $37,40-39,59-54,59-56,59-56,59-55$, \\
& $59-63,69-47,69-49,69-68,75-70,75-$ \\
& $69,75-74,80-77,80-77,80-79,80-81$, \\
& $100-92,100-94,100-98,100-99,103-$ \\
& $100,113-17,113-32,114-32$ \\
\hline \multirow{2}{*}{ Voltage magnitude (\#bus) } & $4,10,12,18,25,27,36,40,59,73,76$, \\
& $82,86,92,107,111,112,117$ \\
\hline & $1-2,2-12,3-5,5-6,6-7,9-10,4-11,5-$ \\
& $11,7-12,12-14,14-15,16-17,17-18$, \\
& $21-22,23-24,28-29,30-17,17-31,23-$ \\
& $32,34-36,37-40,39-40,40-41,43-44$, \\
& $34-43,46-48,45-49,51-52,52-53,54-$ \\
& $55,56-57,50-57,51-58,59-60,60-62$, \\
& $64-65,62-67,68-65,47-69,71-72,71-$ \\
& $73,69-75,74-75,76-77,78-79,81-80$, \\
& $77-82,84-85,86-87,85-88,91-92,92-$ \\
& $93,93-94,94-95,82-96,92-100,95-96$, \\
& $98-100,99-100,100-101,101-102$, \\
& $100-106,105-107,105-108,108-109$, \\
& $103-110,109-110,110-112,17-113$, \\
& $27-115,114-115,75-118,76-118$ \\
\hline & $3,4,8,12,13,16,15,19,20,22,24$, \\
& $25,27,31,33,35,36,42,44,46,47$, \\
& $49,52,53,54,55,61,66,70,72,74$, \\
& $77,79,83,85,86,89,90,92,94,96$, \\
& $97,98,99,102,104,105,110,111$, \\
& $112,116,117,118$ \\
\hline & \\
&
\end{tabular}

Table 6 Results for the IEEE 14 test system

\begin{tabular}{|c|c|c|c|c|c|}
\hline \multirow{2}{*}{ System } & Set & $\sigma_{\Sigma}^{2}$ & $\xi$ & Iteration & Time / s \\
\hline \multirow{5}{*}{ IEEE14 } & Set 1 & $7,9950 \times 10^{-5}$ & 0,4502 & 4,96 & 0,14 \\
\cline { 2 - 6 } & Set 2 & $7,5165 \times 10^{-5}$ & 0,4244 & 5,48 & 0,16 \\
\cline { 2 - 6 } & Set 3 & $6,0622 \times 10^{-5}$ & 0,4049 & 4,95 & 0,05 \\
\cline { 2 - 6 } & Set 4 & $1,8831 \times 10^{-5}$ & 0,1174 & 5,00 & 0,05 \\
\cline { 2 - 6 } & Set 5 & $7,0053 \times 10^{-6}$ & 0,0290 & 5,00 & 0,03 \\
\cline { 2 - 6 } & Set 6 & $9,9855 \times 10^{-7}$ & 0,0282 & 4,15 & 0,01 \\
\cline { 2 - 6 } & Set 7 & $9,9007 \times 10^{-7}$ & 0,0280 & 4,29 & 0,01 \\
\hline
\end{tabular}

The visual results are provided only for the Croatian transmission power system due to space limitations. The results are given for a part of the system observable by the PMUs, since the complete power system that is simulated 
comprises $110 \mathrm{kV}, 220 \mathrm{kV}$ and $400 \mathrm{kV}$ voltage levels, with 200 buses and 287 branches in total. Fig. 2 and Fig. 3 present the errors of estimated voltage angles and magnitudes for the PMU buses. Fig. 4 and Fig. 5 give the errors of calculated power flows based on the estimated power system state.

Table 7 Results for the IEEE 30 test system

\begin{tabular}{|c|c|c|c|c|c|}
\hline \multirow{2}{*}{ System } & Set & $\sigma_{\Sigma}^{2}$ & $\xi$ & Iteration & Time / s \\
\hline \multirow{5}{*}{ IEEE30 } & Set 1 & $2,5582 \times 10^{-5}$ & 0,3760 & 4,58 & 0,22 \\
\cline { 2 - 6 } & Set 2 & $1,6668 \times 10^{-5}$ & 0,2898 & 4,63 & 0,18 \\
\cline { 2 - 6 } & Set 3 & $1,8297 \times 10^{-5}$ & 0,2234 & 4,83 & 0,02 \\
\cline { 2 - 6 } & Set 4 & $1,0695 \times 10^{-5}$ & 0,0760 & 4,00 & 0,06 \\
\cline { 2 - 6 } & Set 5 & $3,4336 \times 10^{-6}$ & 0,0257 & 5,00 & 0,06 \\
\cline { 2 - 6 } & Set 6 & $6,3650 \times 10^{-7}$ & 0,0326 & 5,00 & 0,09 \\
\cline { 2 - 6 } & Set 7 & $4,7826 \times 10^{-7}$ & 0,0243 & 4,00 & 0,04 \\
\hline
\end{tabular}

Table 8 Results for the IEEE 57 test system

\begin{tabular}{|c|c|c|c|c|c|}
\multicolumn{7}{c}{ Table 8 Results for the IEEE 57 test system } \\
\hline \multirow{2}{*}{ System } & Set & $\sigma_{\Sigma}^{2}$ & $\xi$ & Iteration & Time / s \\
\hline \multirow{5}{*}{ IEEE57 } & Set 1 & $1,3508 \times 10^{-3}$ & 0,3080 & 5,00 & 0,21 \\
\cline { 2 - 6 } & Set 2 & $1,3376 \times 10^{-3}$ & 0,2488 & 5,00 & 0,25 \\
\cline { 2 - 6 } & Set 3 & $1,2346 \times 10^{-3}$ & 0,1970 & 5,00 & 0,09 \\
\cline { 2 - 6 } & Set 4 & $1,2981 \times 10^{-3}$ & 0,0694 & 5,00 & 0,10 \\
\cline { 2 - 6 } & Set 5 & $9,0099 \times 10^{-4}$ & 0,0207 & 6,02 & 0,15 \\
\cline { 2 - 6 } & Set 6 & $8,9501 \times 10^{-4}$ & 0,0210 & 5,00 & 0,09 \\
\cline { 2 - 6 } & Set 7 & $8,5960 \times 10^{-4}$ & 0,0211 & 4,95 & 0,11 \\
\hline
\end{tabular}

Table 9 Results for the IEEE 118 test system

\begin{tabular}{|c|c|c|c|c|c|}
\hline \multicolumn{7}{|c|}{ Table 9 Results for the IEEE 118 test system } \\
\hline \multirow{5}{*}{ System } & Set & $\sigma_{\Sigma}^{2}$ & $\xi$ & Iteration & Time / s \\
\hline \multirow{5}{*}{ IEEE1 18 } & Set 1 & $5,7932 \times 10^{-4}$ & 0,6809 & 4,96 & 0,40 \\
\cline { 2 - 6 } & Set 2 & $5,0315 \times 10^{-4}$ & 0,6696 & 5,03 & 0,48 \\
\cline { 2 - 6 } & Set 3 & $4,2007 \times 10^{-4}$ & 0,6301 & 5,13 & 0,41 \\
\cline { 2 - 6 } & Set 4 & $2,1264 \times 10^{-4}$ & 0,5872 & 4,55 & 0,30 \\
\cline { 2 - 6 } & Set 5 & $1,1428 \times 10^{-4}$ & 0,4598 & 5,00 & 0,40 \\
\cline { 2 - 6 } & Set 6 & $7,0962 \times 10^{-5}$ & 0,4574 & 4,99 & 0,37 \\
\cline { 2 - 6 } & Set 7 & $5,4647 \times 10^{-5}$ & 0,9275 & 4,84 & 0,55 \\
\hline
\end{tabular}

Table 10 Results for the Croatian power system

\begin{tabular}{|c|c|c|c|c|c|}
\hline \multirow{2}{*}{ System } & Set & $\sigma_{\Sigma}^{2}$ & $\xi$ & Iteration & Time / s \\
\hline \multirow{5}{*}{ CRO } & Set 1 & $1,4086 \times 10^{-5}$ & 0,2692 & 4,00 & 2,08 \\
\cline { 2 - 6 } & Set 2 & $1,1743 \times 10^{-5}$ & 0,2714 & 4,36 & 2,71 \\
\cline { 2 - 6 } & Set 3 & $1,1156 \times 10^{-5}$ & 0,2594 & 4,38 & 2,52 \\
\cline { 2 - 6 } & Set 4 & $1,2344 \times 10^{-5}$ & 0,1430 & 4,17 & 1,93 \\
\cline { 2 - 6 } & Set 5 & $3,5459 \times 10^{-6}$ & 0,0290 & 4,00 & 2,07 \\
\cline { 2 - 6 } & Set 6 & $3,5153 \times 10^{-6}$ & 0,0292 & 4,94 & 3,13 \\
\cline { 2 - 6 } & Set 7 & $3,5760 \times 10^{-6}$ & 0,8628 & 4,00 & 2,39 \\
\hline
\end{tabular}
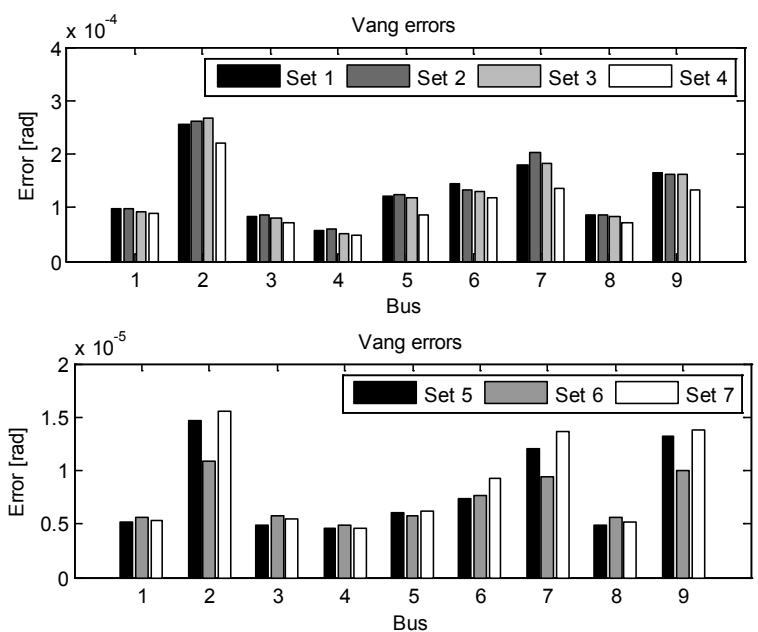

Figure 2 Voltage angle errors for the Croatian power system
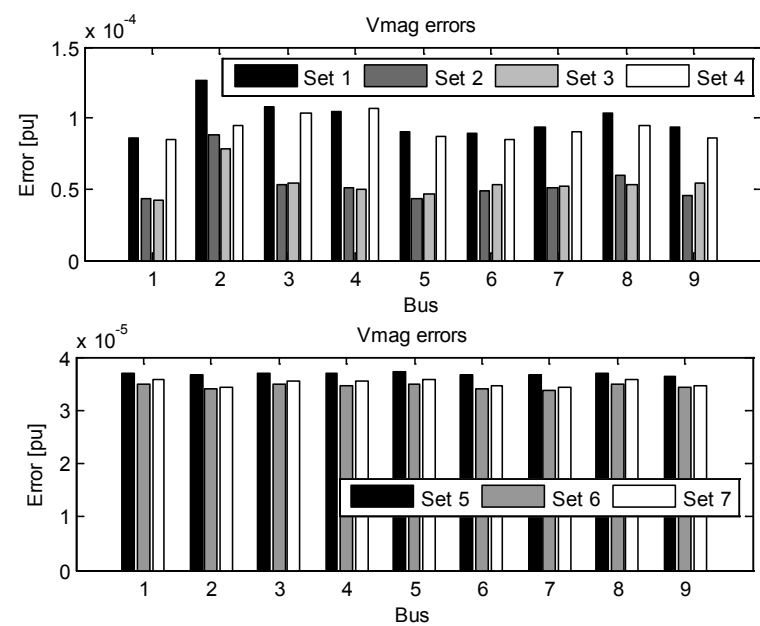

Figure 3 Voltage magnitude errors for the Croatian power system
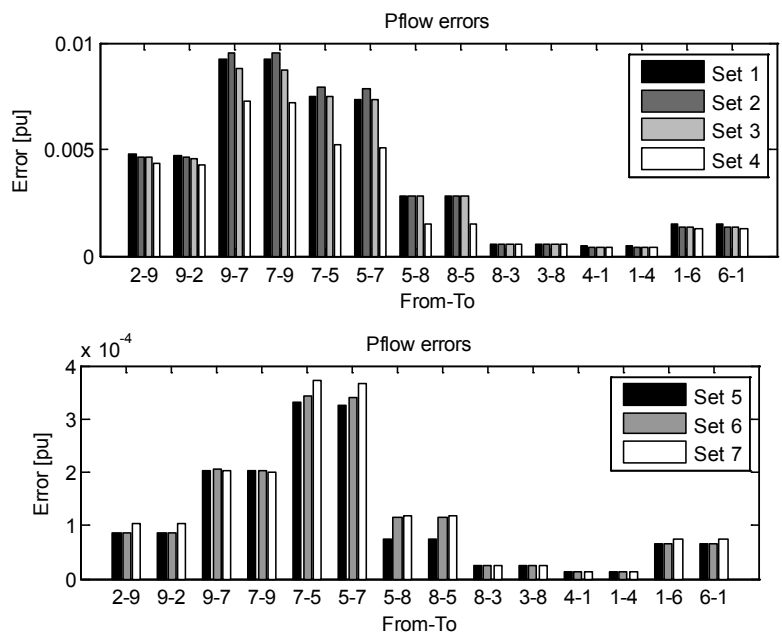

Figure 4 Active power flow errors for the Croatian power system
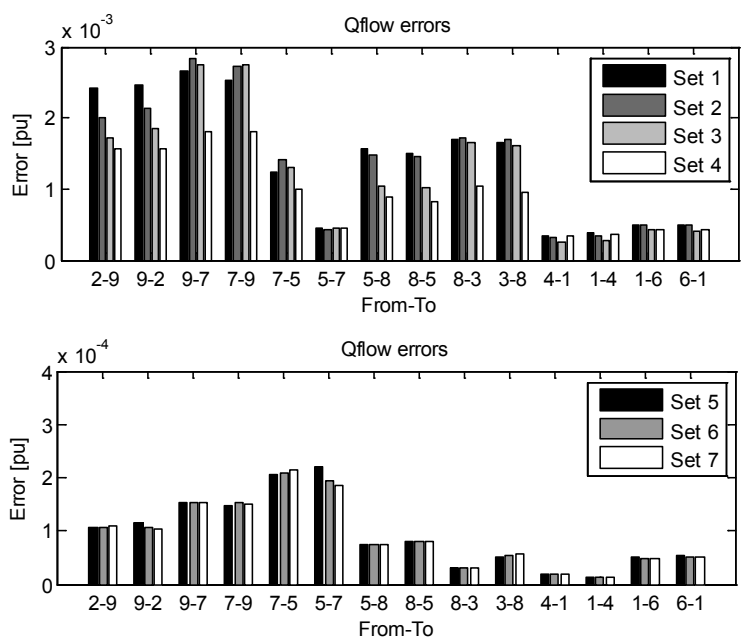

Figure 5 Reactive power flow errors for the Croatian power system

The obtained results indicate that the inclusion of the voltage magnitudes measured by the PMUs and the pseudo-measurements computed from the measured voltage and current synchrophasors contribute to the enhancement of the state estimator performance. With the increase in the number of measurements, the accuracy of the state estimation and the filtering of the measurement errors are improved. With the change of the set of measurements the computation convergence and speed are within the acceptable limits for all the test systems. As 
already explained, in comparison with the Set 6 that takes only the voltage magnitudes, the Set 7 also comprises the angles of the voltages measured by the PMUs and calculated as the pseudo-voltages. The analysis of the results indicates that there is a relatively small difference between the results obtained by using the Set 6 in comparison with the Set 7.

\section{Conclusions}

The set of the conventional measurements used in the state estimator is expanded with the voltage magnitudes directly measured by the PMUs and the pseudomeasurements computed by using the available voltage and current phasors. Appropriate weight factors are assigned to the calculated measurements by using the uncertainty propagation theory and the iterative procedure with equality constraints for null power injections is applied. The methodology was tested on the IEEE test systems with 14, 30, 57 and 118 buses. As an example of the real power system, the Croatian transmission system model was used, with the real locations of SCADA and PMU measurements.

The pseudo-measurements can be calculated independently of the state estimator iterative procedure, and therefore, this approach is noninvasive to the existing state estimator software in the EMS, since the measurement vector consists of the same type of measurements used for the classical state estimator and there is no need for a change in the structure of the Jacobian matrix. The obtained simulation results indicate that the inclusion of the pseudo-measurements into the measurement vector improves the state estimator performance as it provides the more accurate state estimation with enhanced filtering of the measurement errors.

The inclusion of the voltage angles directly measured by the PMUs and the angles of the calculated pseudovoltages does not significantly improve the state estimator performance. On the other hand, the drawback of the inclusion of the voltage angles into the set of measurements is that it would require modifications of the existing state estimator software in the control centre. It can, therefore, be suggested that for the initial stage of the inclusion of the synchrophasors into the state estimator the measurements without the voltage angles are used until the power utility decides to modernize its EMS and implement some of the more advanced hybrid or linear models of the state estimator.

\section{References}

[1] Phadke, A. G.; Thorp, J. S. Synchronized phasor measurements and their applications. Springer, SAD, 2008.

[2] Terzija, V.; Valverde, G.; Cai, D.; Regulski, P.; Madani, V.; Fitch, J.; Skok, S.; Begovic, M.; Phadke, A. G. Wide Area Monitoring, Protection and Control of Future Electric Power Networks. // Proceedings of IEEE. 99, 1(2011), pp. 80-93. DOI: 10.1109/JPROC.2010.2060450

[3] Bi, T. S.; Qin, X. H.; Yang, Q. X. A novel hybrid state estimator for including synchronized phasor measurements. // Electric Power Systems Research. 78, 8(2008), pp. 13431352. DOI: 10.1016/j.epsr.2007.12.002
[4] Valverde, G.; Chakrabarti, S.; Kyriakides, E.; Terzija, V. A constrained formulation for hybrid state estimation. // IEEE Transactions on Power Systems. 26, 3(2011), pp. 11021109. DOI: 10.1109/TPWRS.2010.2079960

[5] Chakrabarti, S.; Kyriakides, E.; Ledwich, G.; Ghosh, A. Inclusion of PMU current phasor measurements in a power system state estimator. // IET Generation, Transmission \& Distribution. 4, 10(2010), pp. 1104-1115. DOI: 10.1049/ietgtd.2009.0398

[6] Chakrabarti, S.; Kyriakides, E.; Valverde, G.; Terzija, V. State estimation including synchronized measurements. // Proceedings of the IEEE Power Tech conference / Bucharest, 2009, pp. 1-5. DOI: 10.1109/ptc.2009.5282018

[7] Asprou, M.; Kyriakides, E. Enhancement of hybrid state estimation using pseudo flow measurements. // Proceedings of the Power and Energy Society General Meeting / Detroit, 2011, pp. 1-7. DOI: 10.1109/pes.2011.6039529

[8] Kirincic, V.; Skok, S.; Marusic, A. A Hybrid Constrained State Estimator with Pseudo Injection Measurements. // PrzeglądElektrotechniczny. 89, 8(2013), pp. 137-142.

[9] Abur, A.; Gomez-Exposito, A. Power System State Estimation: Theory and Implementation. Marcel Dekker, New York, 2004. DOI: 10.1201/9780203913673

[10] Monticelli, A. State Estimation in Electric Power Systems: A Generalized Approach. Kluwer Academic Publishers, Massachusetts, 1999. DOI: 10.1007/978-1-4615-4999-4

[11] Chakrabarti, S.; Kyriakides, E.; Albu, M. Uncertainty in Power System State Variables Obtained Through Synchronized Measurements. // IEEE Transactions on Instrumentation and Measurement. 58, 8(2009), pp. 24522458. DOI: $10.1109 /$ TIM.2009.2016387

[12] ISO-IEC-OIML-BIPM: Guide to the Expression of Uncertainty in Measurement, 1992.

[13] Asprou, M.; Kyriakides, E.; Albu, M. The effect of parameter and measurement uncertainties on hybrid state estimation. // Proceedings of the Power and Energy Society General Meeting / San Diego, 2012, pp.1-8. DOI: 10.1109/pesgm.2012.6345104

[14] Christie, R. Power system test archive. 1999. URL: $\mathrm{http} / / / \mathrm{www}$. ee.washington.edu/research/pstca/ (29.04.2013)

\section{Authors' addresses}

Vedran Kirincic, PhD, assistant professor

University of Rijeka, Faculty of Engineering, Department of Electric Power Systems,

Vukovarska 58, 51000 Rijeka, Croatia

E-mail: vedran.kirincic@riteh.hr

Srdjan Skok, PhD, associate professor

University of Rijeka, Faculty of Engineering,

Department of Electric Power Systems,

Vukovarska 58, 51000 Rijeka, Croatia

E-mail:srdjan.skok@riteh.hr

Dubravko Frankovic, PhD, assistant professor

University of Rijeka, Faculty of Engineering,

Department of Electric Power Systems,

Vukovarska 58, 51000 Rijeka, Croatia

E-mail: dubravko.frankovic@riteh.hr 